\title{
Enhancing polyp detection: technological advances in colonoscopy imaging
}

\author{
Antonio Lee, Nicholas Tutticci \\ Endoscopy Unit, Queen Elizabeth II Jubilee Hospital, Brisbane, Australia \\ Contributions: (I) Conception and design: None; (II) Administrative support: None; (III) Provision of study materials or patients: None; (IV) \\ Collection and assembly of data: None; (V) Data analysis and interpretation: None; (VI) Manuscript writing: Both authors; (VII) Final approval of \\ manuscript: Both authors. \\ Correspondence to: Dr. Nicholas Tutticci, BSc, MBBS, FRACP. Endoscopy Unit, Queen Elizabeth II Jubilee Hospital, Corner Kessels and Troughton \\ Road, Coopers Plains, Brisbane 4108, Australia. Email: Nicholas.Tutticci@health.qld.gov.au.
}

\begin{abstract}
The detection and removal of polyps at colonoscopy is core to the current colorectal cancer (CRC) prevention strategy. However, colonoscopy is flawed with a well described miss rate and variability in detection rates associated with incomplete protection from CRC. Consequently, there is significant interest in techniques and technologies which increase polyp detection with the aim to remedy colonoscopy's ills. Technologic advances in colonoscope imaging are numerous and include; increased definition of imaging, widening field of view, virtual technologies to supplant conventional chromocolonoscopy (CC) and now computer assisted detection. However, despite nearly two decades of technologic advances, data on gains in detection from individual technologies have been modest at best and heterogenous and conflicted as a rule. This state of detection technology science is exacerbated by use of relatively blunt metrics of improvement without consensus, the myopic search for gains over single generations of technology improvement and an unhealthy focus on adenomatous lesions. Yet there remains cause for optimism as detection gains from new technology, while small, may still improve CRC prevention. The technologies are also readily available in current generation colonoscopes and have roles beyond simply detection such as lesion characterization, further improving their worth. Coupled with the imminent expansion of computer assisted detection the detection future from colonoscope imaging advances looks bright. This review aims to cover the major imaging advances and evidence for improvement in polyp detection.
\end{abstract}

Keywords: Colonoscopy; polyp; detection; imaging; high definition (HD); virtual chromoendoscopy; AI; advances

Received: 06 December 2019; Accepted: 17 January 2020; Published: 25 October 2021.

doi: $10.21037 /$ tgh.2020.02.05

View this article at: http://dx.doi.org/10.21037/tgh.2020.02.05

\section{Introduction}

The colonoscopic detection and removal of polyps is central to the current paradigm of colorectal cancer (CRC) prevention. Despite its key role, colonoscopy is imperfect in this task. Tandem colonoscopy studies consistently show up to $25 \%$ of adenomas are missed and substantial variability in adenoma detection rates between Colonoscopists is the norm. Alarmingly, lower detection rates are associated with higher risk for interval CRC (1-4). Intuitively the remedy to colonoscopy's imperfection is to improve detection and this prevailing narrative has driven the development and evolution of multiple technologies such that the major colonoscope manufacturers all currently produce high definition (HD) imaging systems with one or more integrated detection technologies (Olympus, Fujfilm and Pentax, Tokyo, Japan) (5). New colonoscope systems have even been developed specifically around new detection technology such as widening field of view (FUSE EndoChoice Inc., Alpharetta, GA, USA) (6). Despite imaging advances gathering pace since the early 2000s the 
impact on detection has been disappointing. Improvements from individual technology advances are marginal or modest in positive studies but balanced by large numbers of heterogenous or negative results. This is reflected in recent guidelines which suggest technologic advancements can be used but fall short of recommending routine use in average risk colonoscopy (7). The increasingly vast number of detection technology studies suffer from common limitations; the central two being an overly narrow focus on adenomatous polyp detection and secondly reporting only averaged detection rates from multiple Colonoscopists. Both are problems. Firstly, detection of sessile serrated lesions (SSLs) in addition to adenomas is of critical importance as they, like adenomas, are variably detected. More importantly SSLs are precursors in a CRC pathway which appears overrepresented in interval CRC $(8,9)$. A hypothetical technology which improves adenoma detection yet has no, or worse, a negative impact on serrated lesion detection may fail to achieve optimal CRC prevention. The fixation on adenomas is compounded by the focus on the adenoma detection rate (ADR), whilst undoubtedly established and important, may be too blunt to evaluate subtle detection gains in new technologies. Common throughout the detection literature are studies without significant difference in ADR but significant improvements in diminutive or flat adenoma detection or reduction in adenoma miss rates. There is no consensus on what metrics should be used and what represents a clinically meaningful detection gain. The second core issue is that the provision of averaged detection rates may obscure assessment of the real value of new technologies. A generally accepted paradigm is that interventions which will improve the detection rate of the lowest detectors are likely to be of more overall clinical value than improving that of high detectors. Studies which do not routinely report whether detection gains are seen in this former group limit the practical remedial value of that technology. Furthermore, the inclusion of both high and low detectors in a technology study may blunt averaged detection gains if high detectors, already operating nearer the boundaries of detection, are not similarly aided by the study technology. Adding to this a myriad of additional factors require consideration when reviewing the literature, such as; heterogeneity in reporting on training programs and learning curves in new technologies, the combination multiple generations of imaging technology in metaanalyses and the inherent limitation that while imaging studies may be randomized, blinding is usually not possible.
One explanation for the generally meagre improvements in detection seen with imaging technology advances is that imaging represents only a single step in the multi-step process from colonoscopy preparation through to detection and polyp removal for histopathologic assessment. Ideal bowel preparation, optimal colonoscopy technique and the aide of distal attachments culminate in the exposure of colonic mucosa to the imaging technology and each of these have been demonstrated to individually impact on detection (10-12). In a recent network-meta-analysis, Facciorusso et al. concluded that while there were detection gains for most technologies (distal caps or imaging enhancements) there was limited evidence for superiority of any one single technology (13).

The conclusion in the current ESGE guideline is that most of the current technologies provide only "marginal detection gains" however we believe there is still a case for optimism (7). Most of the imaging advances covered in this review are already available on current generation colonoscopes, so Colonoscopists already have an opportunity to gain experience day to day. These technologies also have established benefits beyond detection such as characterization and real time prediction of polyp histology and the assessment of polypectomy scars at surveillance $(7,14)$. When a technology has multiple practical benefits its inclusion, and use, is more likely and incorporation into successive colonoscope systems more readily justified. Perhaps more importantly, technology advances are still arriving. The current paradigm of detection imaging technology has recently been disrupted by the advent of computer aided detection (CAD) systems which have capacity to detect polyps and relay this to the Colonoscopist. In this review we aim to cover the major areas of colonoscope imaging advances with a focus on the evidence base for detection gains for each technology.

\section{Colonoscope imaging definition and field of view}

\section{$H D$}

Detection of mucosal abnormalities in the gastrointestinal tract is primarily dependent on the image seen by the endoscopist and the ability to recognize subtle differences in mucosal characteristics. The ability to discriminate these fine details was greatly advanced with the advent of HD endoscopes in the early 2000s. Prior to HD endoscopes, the image resolution achieved by standard definition endoscopes was approximately 370,000 pixels (15). 
With improvements in charge-coupled device chips and complementary metal oxide semi-conductor (CMOS) technology, HD endoscopes now have image resolutions ranging from 850,000 pixels to more than 1 million pixels. Disappointingly these advances in definition have only translated into marginal gains in detection. Data from early studies of early HD systems were presented in a 2011 metaanalysis which included 4,422 patients and demonstrated an increased adenoma diagnostic yield of $3.5 \%$ for HD over SD (16). Study heterogeneity, non-randomized studies and technological limitations of early HD systems may have contributed to the limited detection difference. However, optimism that randomized studies of more recent HD technology would demonstrate more impressive detection gains are yet to materialize. A multicentre trial in the United Kingdom of 262 patients in the UK National Bowel Cancer Screening Program randomized patients to either SD (Olympus Lucera System, Toyko, Japan) or the HD (Pentax HiLine system, Tokyo, Japan) did not demonstrate a difference in polyp or adenoma detection, though HD was superior in the detection of flat adenomas $(18.6 \%$ vs. $5.2 \%$; $\mathrm{P}<0.001)(17)$. Comparison of SD and HD within and between endoscopy systems was assessed in an ambitious study in which patients were randomized to either SD or HD WL or SD or HD virtual chromocolonoscopy (VCC) with one of three endoscopy systems (Fujifilm, Olympus, or Pentax, Tokyo Japan.) Acknowledging the study failed to reach target recruitment, there was no difference in ADR between SD or HD (18). Interesting HD white light (WL) did have a higher SSL detection $(8.3$ vs. $3.8 ; \mathrm{P}<0.01)$ than SD WL.

A possible explanation for the limited detection improvements seen with HD is that while there are incremental gains between successive generations of endoscopy system these are small and that true detection improvement may be better measured when comparing colonoscopes over two generations of definition improvement $(19,20)$. A large retrospective German study found a significantly difference in adenoma detection between two ( $33 \%$ vs. $27 \%$; $\mathrm{P}=0.01$ ) but not one generation of colonoscope technology (19). This hypothesis was further tested in a prospective multicentre randomized tandem trial which compared the adenoma miss rate in 856 patients at high risk for adenomas (symptomatic patients, polyp surveillance or positive family history) between the Olympus Exera 160-C and Exera III 190-C systems (Olympus, Tokyo, Japan) (20). HD colonoscopy had a significantly lower adenoma miss rate $(16.6 \%$ vs. $30.2 \% ; \mathrm{P}=0.001)$ and higher
ADR (43.8\% vs. 36.5\%; $\mathrm{P}=0.03$ ) than $\mathrm{SD}$ (20). Interestingly in contrast to adenomas, no difference in SSL detection rate or missed SSLs was demonstrated $(5.8 \%$ vs. $4.5 \% ; \mathrm{P}=0.361$, $2.1 \%$ vs. $1.2 \% \mathrm{P}=0.308$ ) though this should be interpreted within the context of a relatively low overall SSL detection rate. A second randomized control trial (RCT) without tandem colonoscopy of 1,221 average risk screening patients however failed to demonstrate a significant difference in ADR (HD 32\% vs. SD 28\%; P=0.01) though HD did detect an overall greater number of diminutive adenomas in the cohort (135 vs. 97; $\mathrm{P}=0.002$ ) (21). Counterintuitively a lower overall detection of SSLs was seen the HD compared to the SD group (62 vs. 81; $\mathrm{P}=0.005)$ (21).

Overall HD colonoscopy appears to be associated with a marginal increase in adenoma detection which may be more marked when comparing over multiple generations of colonoscope imaging technology. There is no clear data to support HD improving SSL detection.

\section{Field of view}

Despite the theoretical advantage of a greater field of view, randomized trials have failed to support this technology advancement in routine colonoscope systems. Two RCTs have compared detection between colonoscopes with 140 degree and 170 degree field of view and failed to demonstrate a difference $(22,23)$. The possibility that the addition of more than 30 degrees of view is required to improve detection has been addressed with several systems such as FUSE with 330 degrees of view. Meta-analysis of the initial 8 FUSE RCTs demonstrated reduced adenoma miss rate but no difference in ADR or SSL detection rates and two subsequent RCTs have demonstrated consistent findings $(6,24,25)$. Whilst FUSE and other extra wide field of view technologies [EWAVE (Olympus, Tokyo, Japan)], Third Eye Retroscope, Panoramic (Avantis Medical Systems, Sunnyvale, CA, USA), and NaviAid G-EYE balloon colonoscope (SMART Medical Systems Ltd, Ra'anana, Israel) highlight the potential of benefits of an expanded field of view, none have achieved widespread uptake for use in routine colonoscopy. The simple hypothesis that increasing the monitor size on which the endoscopic image is displayed without a wider field of endoscopic view could improve detection was examined in a single centre RCT where no difference in ADR was seen between 19- and 32-inch displays (26).

Overall there is little evidence to support significant detection gains from extra-wide field of view technology 



Figure 1 Flat adenomatous polyps and background colonic mucosa highlighted with chromocolonoscopy (A) $5 \mathrm{~mm}$ flat (Paris 0-IIa) adenoma. A $7 \mathrm{~mm}$ flat (Paris 0-IIa) adenoma detected with chromocolonoscopy (B) and viewed with near focus magnification (C).

which is reflected in limited inclusion into routine practice. More study in this area may be required.

\section{Chromocolonoscopy (CC) and VCC}

\section{$C C$}

CC was first described in 1977 and has consistently been associated with improved detection in the majority of studies with increases in overall polyp detection, adenoma detection and serrated polyp detection rates (27-30). Whilst not a universally considered a technologic imaging advance, a brief review of CC is warranted as virtual CC technologies aim to replicate and supplant CC, thus it remains the yardstick by VCC technologies should be judged.

$\mathrm{CC}$ involves colonic inspection after the application of a contrast dye, indigo-carmine or methylene blue. CC highlights the topography and microtopography of the colonic mucosa, reflected in increased flat and diminutive adenoma detection (29,31) (Figure 1). A 2016 Cochrane review of seven randomized controlled trials concluded, despite heterogeneity in patient cohorts, that CC increased both the mean number of polyps detected as well as the number of neoplastic lesions found; OR detection of at least one polyp 1.87 (95\% CI: 1.51 to 2.3) (29). With the widespread introduction of HD imaging which was already associated with detection gains the question of whether CC still conferred additional detection was assessed by Kahi et al. in 2010 (31). Six hundred and sixty patients were randomised to HD CC or white light (WL). Consistent with previous studies the $\mathrm{CC}$ mean procedure time was significantly longer (30.6 vs. $21.9 \mathrm{~min} ; \mathrm{P}<0.001$ ) however the mean examination time was equivalent $(7.9$ vs. $7.6 \mathrm{~min}$;
$\mathrm{P}=0.12)$. The higher $\mathrm{CC} \operatorname{ADR}(55.5 \%$ vs. $48.4 \%)$ was not statistically significant however CC did detect a higher proportion of flat adenomas, diminutive adenomas and a higher number of polyps per patient (31).

In addition to improved adenoma detection, increased proximal serrated lesion detection has also been demonstrated in a RCT where CC was compared with SD WL colonoscopy (12\% vs. 6\%; OR 1.96; $\mathrm{P}=0.012)$ though again the $\mathrm{CC}$ mean procedure time was significantly longer (36.8 vs. 30.6 minutes) (32).

Despite the benefits of CC, an increase in detection of advanced adenomas has not been demonstrated and guidelines have fallen short of recommending CC use in routine average-risk colonoscopy (28). In addition to the costs of procurement and preparation of the dye and the equipment for delivery, CC has consistently been associated with a time cost of longer withdrawal times, though it is possible these longer times are an inherent component of the improved detection of CC rather than simply an unwanted negative consequence $(7,28,29)$.

It is possible that overcoming the logistic hurdles in delivering CC could reduce the barrier to widespread CC use. This was studied in multi-centre, placebo controlled randomised double blind trial of methylene blue colonic release tablets (MB-MMX) (33). Methylene blue was combined with a $\mathrm{pH}$ and time dependent multimatrix structure designed to release the dye in the colon. A total of 1,249 patients were randomised in the intention to treat analysis with an increase in the detection of at least one adenoma, traditional serrated adenoma or SSL in the MBMMX group (56.29\% vs. $47.81 \%$; $\mathrm{P}<0.01)$ (33).

Overall CC confers significant detection advantages and continues to have a role in detection particularly in high 

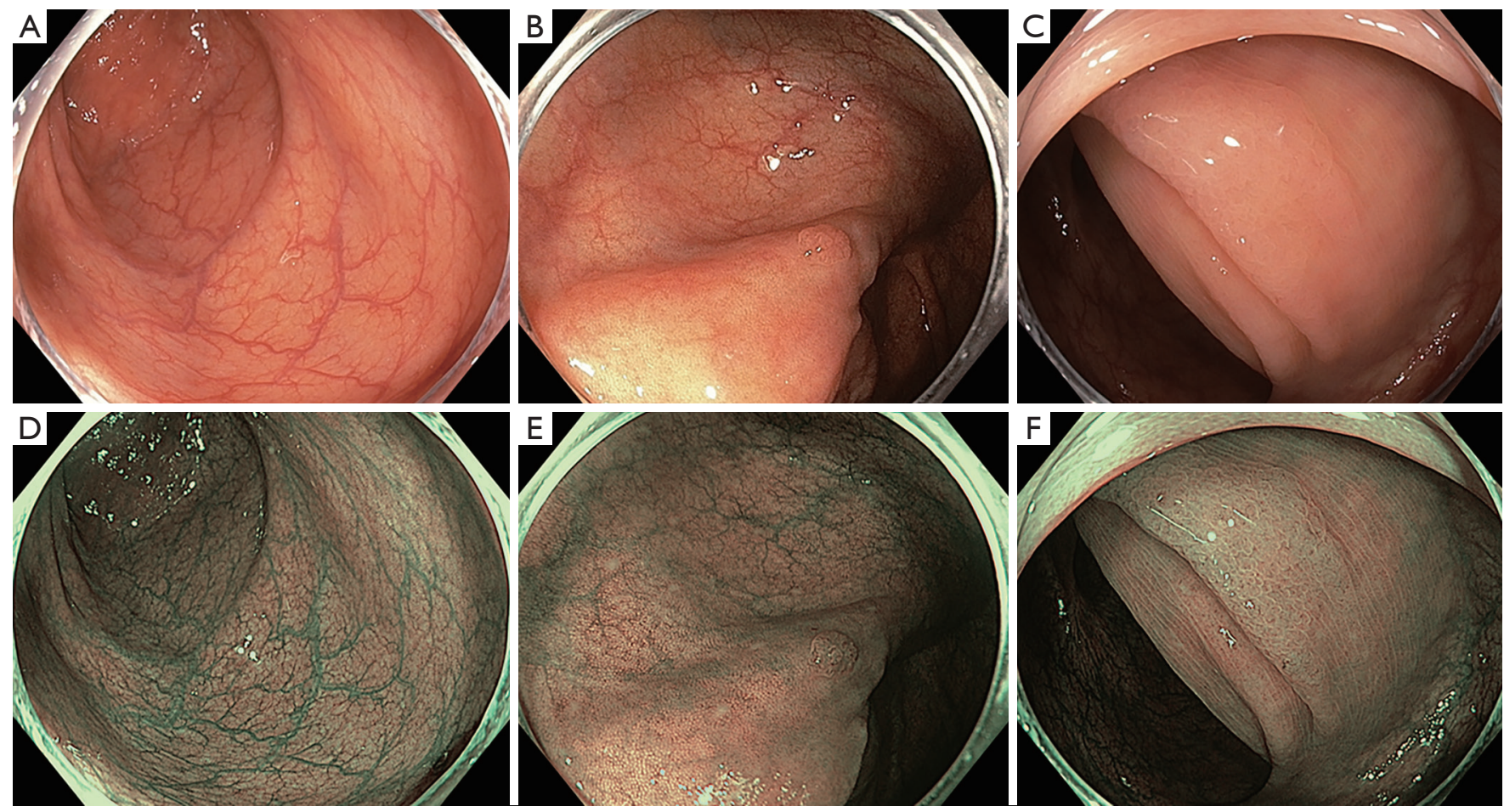

Figure 2 Normal colonic mucosa viewed with high definition white light (HD WL) (A) and narrow band imaging (NBI) (D) Diminutive flat (Paris 0-IIa) adenoma viewed with HD WL (B) and NBI (E). Large flat sessile serrated lesion viewed with HD WL (C) and NBI (F).

risk patient groups. However it is the juxtaposition these benefits with the challenges in implementation that has facilitated interest and research in VCC.

\section{$V C C$}

Push button VCC is now routinely incorporated into HD colonoscope systems either as light filters (NBI, Olympus Tokyo Japan) narrow wavelength laser (BLI/LCI Fujifilm, Tokyo, Japan) or post-image acquisition processing (I-Scan Pentax, FICE Fujifilm, Tokyo, Japan). In principle VCC aims to replicate the enhanced surface contrast and microtopography advantages of CC with simple push button technique rather than the physical spraying of dye in CC. In addition VCC aims to exaggerate the mucosal capillary vascular networks which is hypothesized to improve detection through the absence of the normal background vascular network and, for adenomatous lesions, highlight denser neoplastic vascular network (34). These conceptual advantages of VCC have unfortunately not translated into clear detection gains with evidence of increased detection mixed or limited in effect (7). However current generation
VCC does appear superior to initial VCC technology giving a glimmer of hope to a future role of VCC in routine colonoscopy (34).

\section{Narrow band imaging (NBI)}

Conventional white light colonoscopy has three optical filters covering the visible wavelength range from 400 to $800 \mathrm{~nm}$. NBI is achieved by filtering out the red light bandwidth, leaving a narrowed spectrum of light, at 415 and $540 \mathrm{~nm}$, to penetrate the mucosa less deeply, resulting in increased contrast for surface vessels and structures (5) (Figure 2).

A recent meta-analysis of data from 4,491 individual patients in eleven randomised controlled trials compared the efficacy of NBI to white light colonoscopy (34). Overall, the ADR was $42.3 \%$ for HD-WL vs. $45.2 \%$ for NBI (OR for adenoma detection of $1.14 \mathrm{NBI}$ compared to HDWLE; 95\% CI: 1.01-1.29; $\mathrm{P}=0.04)$. Despite heterogeneity in bowel prep scores, NBI was found to be superior to $\mathrm{WL}$ when bowel prep grade was best compared to only adequate (OR 1.30; 95\% CI: 1.04-1.62; $\mathrm{P}=0.02$ ). ADR was also found 
to be higher only with newer generation "bright" NBI than WLE (OR 1.28; 95\% CI: $1.05-1.56 ; \mathrm{P}=0.02$ ), but not in initial generation NBI. Non-adenomatous polyps (OR 1.24; 95\% CI: 1.06-1.44; $\mathrm{P}=0.008)$, right sided non-adenomatous polyps (OR 1.35; 1.05-1.74; $\mathrm{P}=0.02$ ) and flat polyps (OR 1.24; $95 \%$ CI: $1.02-1.51 ; \mathrm{P}=0.03$ ) were also more likely to be detected with NBI than WL. SSLs are likely to comprise a substantial proportion of non-adenomatous right sided polyps. SSL detection was specifically assessed in recent meta-analysis where the only VCC technology demonstrating gains was NBI (SSL detection rate RR 2.04; 95\% CI: 1.18-3.54; $\mathrm{P}=0.01$ and mean SSLs per patient 0.03 vs. 0.024; $\mathrm{P}<0.001)(35)$.

Studies comparing current generation NBI with CC are limited. Lynch syndrome represents the most common cause of genetic CRC and is typified by rapid adenoma to carcinoma progression with the implication that detection and removal of even diminutive adenomas is important (36). The evaluation of detection techniques and technologies in this setting are therefore informative. While both CC and NBI have demonstrated superior adenoma detection over WL in Lynch patients, even the current generation of bright NBI appears inferior to conventional HD CC $(28,37,38)$.

Overall NBI appears to improve adenoma and SSL detection though in Lynch patients falls short of CC detection rates.

\section{FICE}

Flexible spectral imaging colour enhancement (FICE) is a post-processor technology available on Fujifilm systems. In contrast to NBI, which uses optical light filters, FICE is an image processing technique to select particular wavelengths from an image which is then reconstructed. Similar to NBI, data from the red light bandwidth can be discarded and the image can be created with a narrowed spectrum of green and blue light (5). In 2014, a systematic review and metaanalysis was published which reported no greater yield of adenomas with FICE when compared to HD-WLE (RR 1.09; 95\% CI: 0.97-1.23) (39).

\section{BLI and LCI}

Blue laser imaging (BLI) and linked colour imaging (LCI) were developed by Fujifilm in 2012. Unlike NBI which uses optical light filters, the BLI and LCI imaging modes are generated by two lasers with wavelengths of 410 and
$450 \mathrm{~nm}$ (40). White light endoscopy is achieved through irradiation of phosphor by the $450 \mathrm{~nm}$-wavelenght laser. BLI is proposed to facilitate characterization of mucosal vessels and structures and LCI to increase detection by improving contrast between red coloured lesions and white mucosa (Figure 3).

There have been several randomised control trials for the utility of BLI and LCI in polyp detection (41-44). BLI was associated with a higher number of adenomas per patient than WL and in a tandem colonoscopy study BLI followed by WL, had a lower polyp miss rate of $1.6 \% v s$. $10.0 \%$ miss rate in the WLE-BLI group (42). More recent studies have focused on LCI for detection as it appears to provide superior polyp "visibility" over BLI (45). A number of RCTs have demonstrated an increased ADR for LCI over WL, 37\% vs. 28\% [95\% (2.39-19.41\%)] (43). LCI also has demonstrated lower adenoma miss rates in the proximal colon than WL (30.6\% vs. 11.8\% $\mathrm{P}=0.02)$ (44). However neither a significant SSL detection rate nor reduced SSL miss rate were observed in these studies $(44,46)$. In contrast a recent small tandem RCT of 44 patients demonstrated substantially superior SSL detection for LCI ( 21.6\% vs. $3.2 \%, \mathrm{P}=0.02)(47)$.

Few studies have directly compared VCC technologies. A recent tandem RCT compared current generation NBI and LCI demonstrating a higher polyp detection rate $(71.3 \%$ vs. $55.9 \%, \mathrm{P}=0.008)$ and serrated polyp detection rate $(34.6 \%$ vs. $22.1 \%, \mathrm{P}=0.02)$ for NBI, however the difference in ADR did reach statistical significance $(51.5 \%$ vs. $39.7 \%, \mathrm{P}=0.05)$ (48). NBI withdrawals were longer, the cause of which is unclear, however as longer withdrawal times were also associated with detection gains further comparative studies are required (48).

Overall LCI appears to improve adenoma detection. Data to support increased detection of SSLs is limited.

\section{I-Scan}

Available on Pentax systems, i-Scan is a post-processing technology with three image enhancement features: surface enhancement, contrast enhancement and tone enhancement. Like FICE, a white-light image can be deconstructed then reconstructed with the aid of software algorithms allowing further modifications as specified by the endoscopist (5) (Figure 4). Initial support for i-Scan technology was based on studies comparing HD i-Scan colonoscopy SD WL colonoscopy (49). Polyp detection rates $(67.9 \%$ vs. $48.1 \%$, 

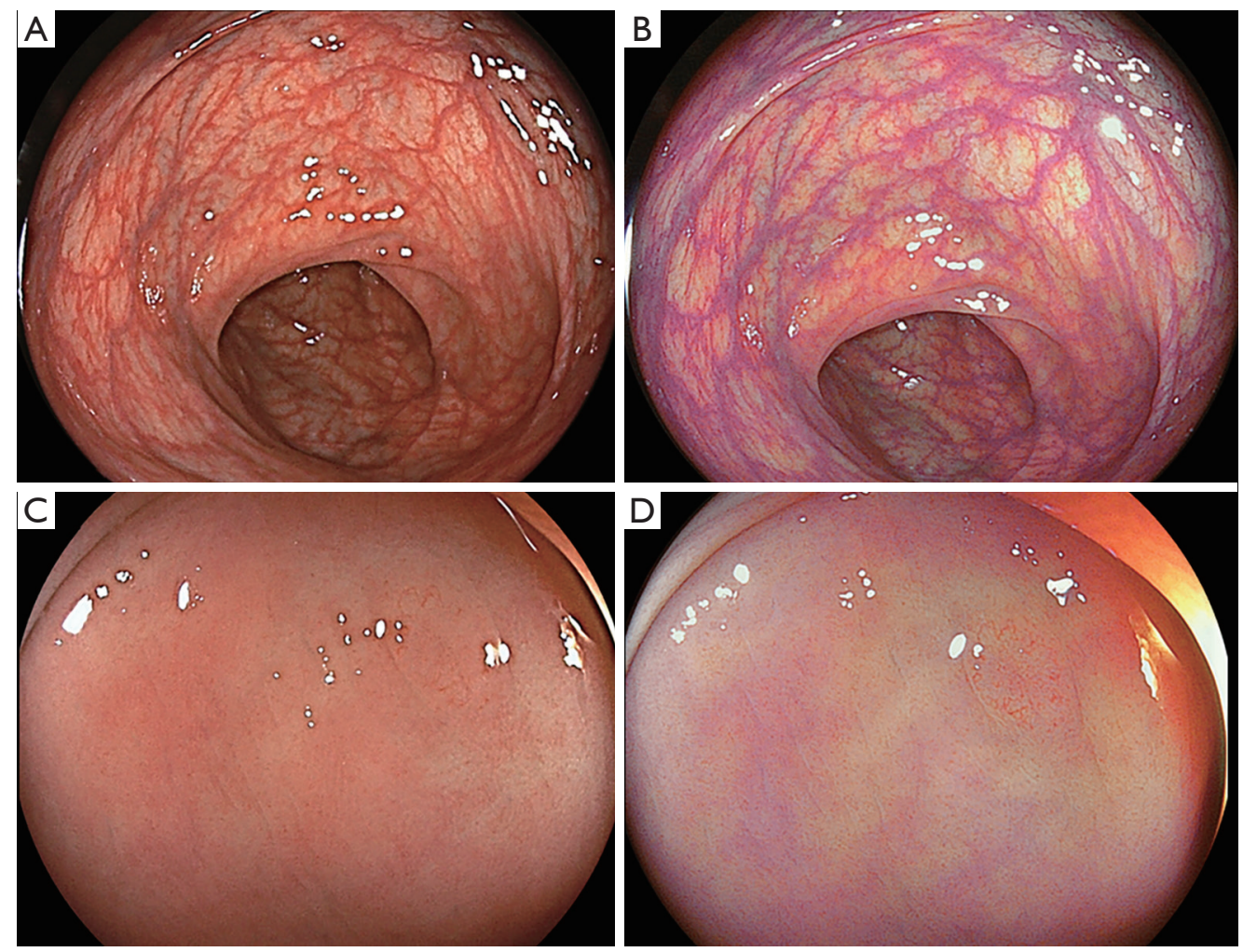

Figure 3 Normal colonic mucosa viewed with high definition white light (HD WL) (A) and linked colour imaging (LCI) (B). Diminutive $3 \mathrm{~mm}$ flat (Paris 0-IIa) adenoma visualized with HD WL (C) and LCI (D).
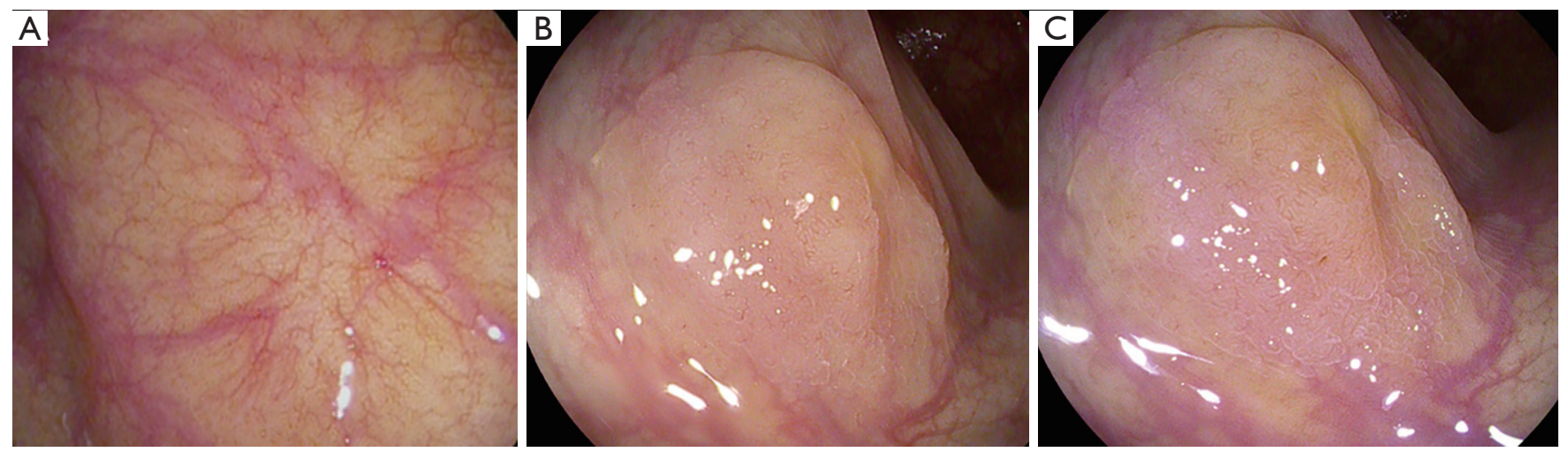

Figure 4 Normal colonic mucosal vascular pattern viewed with I-Scan OE mode 2 (A). A large flat (Paris 0-IIa) sessile serrated lesion with disruption of background colonic mucosal vascular pattern viewed with high definition white light (B) and I-Scan OE mode 2 (C). OE, optical enhancement.

$\mathrm{P} \leq 0.0001)$ and flat polyp detection $(27.8 \%$ vs. $9.9 \%$; $\mathrm{P}=0.04$ ) were higher in the HD i-Scan group (50). However combining HD with VCC and comparing to SD limits the capacity to determine the relative benefit of the VCC technology. A more recent tandem RCT compared HD i-Scan and HD WL colonoscopy in 740 patients with an i-Scan demonstrating a higher ADR for i-Scan $(47.2 \%$ vs. $37.7 \% \mathrm{P}=0.01$ ) (51). No difference in SSL detection was 
seen. In a tandem RCT involving a Lynch patient cohort i-Scan demonstrated substantially lower adenoma miss rate than HD WL $(12 \%$ vs. $62 \%, \mathrm{P}=0.007)$ without difference in ADR (52).

Overall i-Scan appears to improve the detection of adenomas. Data supporting detection of SSLs is limited.

\section{Autofluorescence imaging (AFI)}

AFI is an image enhancing technology that highlights endogenous fluorescence generated from tissue by excitation light $(53,54)$. A proposed advantage of AFI beyond detection is the role of novel characterization; the emitted natural fluorophores of benign and malignant lesions differ hence AFI does not require morphological assessment to assess a lesion (55). Efficacy data for AFI detection is inconsistent as presented in a systematic review and meta-analysis of five tandem studies comparing ADR, PDR, adenoma miss rates (53). There was no difference in $\mathrm{ADR}$ and $\mathrm{PDR}$, however the adenoma miss rate (OR 0.62; 95\% CI: 0.44-0.86; $\mathrm{P}=0.004$ ) was lower with AFI than WL. A more recent multicentre RCT of 802 patients similarly did not show a difference in ADR but did reveal superior flat polyp detection with AFI (0.87; CI 0.78-0.97 vs. 0.53 0.46-0.61) (53).

Overall the benefit of AFI appears limited to the research setting at present.

\section{Computer-aided detection (CAD)}

A substantial facet of the imperfection of colonoscopy is heterogenous human performance, reflected in the significant variability in adenoma and SSL detection rates between Colonoscopists $(3,8)$. The majority of technologies introduced to date have aimed to improve or assist the Colonocopist in the recognition and detection of lesions. $\mathrm{CAD}$ challenges this paradigm, as while in practice it may assist the Colonoscopist with detection, conceptually it has the capacity to automate and replace the detection role of the Colonoscopist (56). Progression from research interest in computer assistance during endoscopy to present where the release of multiple real time systems is imminent, and has been permitted by improvements in computing power and the evolution in machine learning from "hand-crafted" to artificial intelligence "deep learning" (7,56,57).

High accuracy (76.5-96.4\%) and sensitivity (>90\%) has been demonstrated in deep learning CAD studies with a low rate of false positive findings at $7 \%(58,59)$. However these studies assessed CAD colonoscopy video recordings. A recent RCT of CAD during real-time HD colonoscopy in 1,058 patients demonstrated a significantly greater ADR (29.1\% vs. $20.3 \% ; \mathrm{P}<0.001$ ) and mean number of adenomas per patient with $\mathrm{CAD}(0.53$ vs. $0.31 ; \mathrm{P}=0.001)$ where the greatest yield was seen for diminutive adenomas (60).

The major advantage of CAD may be in standardizing colonoscopy by improving low detectors' rates. However further study of the impact of CAD on high and low detectors is required to confirm this. CAD also has potential for assistance with characterization of detected polyps which further supports inclusion into routine colonoscopy (7). Although CAD is promising a number potential limitations of this technology have been raised: (I) the rate of false positives, which could translate to the Colonoscopist having to interpret the additional images and therefore negatively impact colonoscopy efficiency; (II) the potential for deskilling Colonoscopists and finally (III) data security, hacking and the medico legal and regulatory issues as the automation component grows (7). There is no data on real time CAD detection for SSLs.

Overall CAD appears likely to have a role in adenoma detection support with more study required to define the best clinical setting for it use and the impact on SSL detection.

\section{Conclusions}

Despite marginal adenoma detection gains from available imaging technology advances over the last two decades there is cause for optimism. Many imaging advances are already available in daily use and have added benefits outside of detection. The advent of CAD has the significant potential to improve detection and raise the colonoscopy quality bar. SSL detection however can no longer be ignored and the impact on SSL detection must be evaluated in all new detection technologies. We also need consensus on the metrics of detection gain and what represents a clinically significant gain needed to help standardize research moving forward.

\section{Acknowledgments}

We are grateful to Dr. Sneha John MBBS FRACP, Gold Coast University Hospital, AUSTRALIA for providing the images in Figure 3.

Funding: None. 


\section{Footnote}

Provenance and Peer Review: This article was commissioned by the Guest Editors (Krish Ragunath, Philip WY Chiu) for the series "Advanced Endoscopic Imaging of the GI Tract" published in Translational Gastroenterology and Hepatology. The article has undergone external peer review.

Conflicts of Interest: The authors have no conflicts of interest to declare.

Ethical Statement: The authors are accountable for all aspects of the work in ensuring that questions related to the accuracy or integrity of any part of the work are appropriately investigated and resolved.

Open Access Statement: This is an Open Access article distributed in accordance with the Creative Commons Attribution-NonCommercial-NoDerivs 4.0 International License (CC BY-NC-ND 4.0), which permits the noncommercial replication and distribution of the article with the strict proviso that no changes or edits are made and the original work is properly cited (including links to both the formal publication through the relevant DOI and the license). See: https://creativecommons.org/licenses/by-nc-nd/4.0/.

\section{References}

1. Rex DK, Cutler CS, Lemmel GT, et al. Colonoscopic miss rates of adenomas determined by back-to-back colonoscopies. Gastroenterology 1997;112:24-8.

2. van Rijn JC, Reitsma JB, Stoker J, et al. Polyp miss rate determined by tandem colonoscopy: a systematic review. Am J Gastroenterol 2006;101:343-50.

3. Kaminski MF, Regula J, Kraszewska E, et al. Quality indicators for colonoscopy and the risk of interval cancer. N Engl J Med 2010;362:1795-803.

4. Corley DA, Jensen CD, Marks AR, et al. Adenoma detection rate and risk of colorectal cancer and death. $\mathrm{N}$ Engl J Med 2014;370:1298-306.

5. East JE, Vleugels JL, Roelandt P, et al. Advanced endoscopic imaging: European Society of Gastrointestinal Endoscopy (ESGE) Technology Review. Endoscopy 2016;48:1029-45.

6. Kudo T, Saito Y, Ikematsu H, et al. New-generation full-spectrum endoscopy versus standard forwardviewing colonoscopy: a multicenter, randomized, tandem colonoscopy trial (J-FUSE Study). Gastrointest Endosc
2018;88:854-64.

7. Bisschops R, East JE, Hassan C, et al. Advanced imaging for detection and differentiation of colorectal neoplasia: European Society of Gastrointestinal Endoscopy (ESGE) Guideline - Update 2019. Endoscopy 2019;51:1155-79.

8. Hetzel JT, Huang CS, Coukos JA, et al. Variation in the detection of serrated polyps in an average risk colorectal cancer screening cohort. Am J Gastroenterol 2010;105:2656-64.

9. Kahi CJ. How does the serrated polyp pathway alter CRC screening and surveillance? Dig Dis Sci 2015;60:773-80.

10. Rex DK, Imperiale TF, Latinovich DR, et al. Impact of bowel preparation on efficiency and cost of colonoscopy. Am J Gastroenterol 2002;97:1696-700.

11. Rex DK, Hewett DG, Raghavendra M, et al. The impact of videorecording on the quality of colonoscopy performance: a pilot study. Am J Gastroenterol 2010;105:2312-7.

12. Facciorusso A, Del Prete V, Buccino RV, et al. Comparative Efficacy of Colonoscope Distal Attachment Devices in Increasing Rates of Adenoma Detection: A Network Metaanalysis. Clin Gastroenterol Hepatol 2018;16:12091219.e9.

13. Facciorusso A, Triantafyllou K, Murad MH, et al. Compared Abilities of Endoscopic Techniques to Increase Colon Adenoma Detection Rates: A Network Metaanalysis. Clin Gastroenterol Hepatol 2019;17:24392454.e25.

14. Desomer L, Tutticci N, Tate DJ, et al. A standardized imaging protocol is accurate in detecting recurrence after EMR. Gastrointest Endosc 2017;85:518-26.

15. ASGE Technology Committee. High-definition and highmagnification endoscopes. Gastrointestinal Endoscopy 2014;80:919-27.

16. Subramanian V, Mannath J, Hawkey CJ, et al. High definition colonoscopy vs. standard video endoscopy for the detection of colonic polyps: a meta-analysis. Endoscopy 2011;43:499-505.

17. Di Caro S, Fini L, Vega R, et al. Multicentre randomised controlled trial comparing standard and high resolution optical technologies in colorectal cancer screening. Frontline Gastroenterology 2019;10:244-52.

18. Roelandt P, Demedts I, Willekens H, et al. Impact of endoscopy system, high definition, and virtual chromoendoscopy in daily routine colonoscopy: a randomized trial. Endoscopy 2019;51:237-43.

19. Adler A, Wegscheider K, Lieberman D, et al. Factors determining the quality of screening colonoscopy: a 
prospective study on adenoma detection rates, from 12,134 examinations (Berlin colonoscopy project 3, BECOP-3). Gut 2013;62:236-41.

20. Pioche M, Denis A, Allescher HD, et al. Impact of 2 generational improvements in colonoscopes on adenoma miss rates: results of a prospective randomized multicenter tandem study. Gastrointest Endosc 2018;88:107-16.

21. Zimmermann-Fraedrich K, Groth S, Sehner S, et al. Effects of two instrument-generation changes on adenoma detection rate during screening colonoscopy: results from a prospective randomized comparative study. Endoscopy 2018;50:878-85.

22. Deenadayalu VP, Chadalawada V, Rex DK. 170 degrees wide-angle colonoscope: effect on efficiency and miss rates. Am J Gastroenterol 2004;99:2138-42.

23. Fatima H, Rex DK, Rothstein R, et al. Cecal insertion and withdrawal times with wide-angle versus standard colonoscopes: a randomized controlled trial. Clin Gastroenterol Hepatol 2008;6:109-14.

24. Núñez-Rodríguez H, Diez-Redondo P, Perez-Miranda M, et al. Role of Full-spectrum Endoscopy in Colorectal Cancer Screening: Randomized Trial. J Clin Gastroenterol 2019;53:191-6.

25. Facciorusso A, Del Prete V, Buccino V, et al. Fullspectrum versus standard colonoscopy for improving polyp detection rate: A systematic review and meta-analysis. J Gastroenterol Hepatol 2018;33:340-6.

26. Jovani M, Campbell EJ, Hur C, et al. Effect of video monitor size on polyp detection: a prospective, randomized, controlled trial. Gastrointest Endosc 2019;90:254-258.e2.

27. Tada M, Katoh S, Kohli Y, et al. On the dye spraying method in colonofiberscopy. Endoscopy 1977;8:70-4.

28. Kamiński MF, Hassan C, Bisschops R, et al. Advanced imaging for detection and differentiation of colorectal neoplasia: European Society of Gastrointestinal Endoscopy (ESGE) Guideline. Endoscopy 2014;46:435-49.

29. Brown SR, Baraza W, Din S, et al. Chromoscopy versus conventional endoscopy for the detection of polyps in the colon and rectum. Cochrane Database Syst Rev 2016;4:CD006439.

30. Kahi CJ, Li X, Eckert GJ, et al. High colonoscopic prevalence of proximal colon serrated polyps in averagerisk men and women. Gastrointest Endosc 2012;75:515-20.

31. Kahi CJ, Anderson JC, Waxman I, et al. High-definition chromocolonoscopy vs. high-definition white light colonoscopy for average-risk colorectal cancer screening. Am J Gastroenterol 2010;105:1301-7.
32. Hurt C, Ramaraj R, Farr A, et al. Feasibility and economic assessment of chromocolonoscopy for detection of proximal serrated neoplasia within a population-based colorectal cancer screening programme (CONSCOP): an open-label, randomised controlled non-inferiority trial. Lancet Gastroenterol Hepatol 2019;4:364-75.

33. Repici A, Wallace MB, East JE, et al. Efficacy of Per-oral Methylene Blue Formulation for Screening Colonoscopy. Gastroenterology 2019;156:2198-2207.e1.

34. Atkinson NSS, Ket S, Bassett P, et al. Narrow-Band Imaging for Detection of Neoplasia at Colonoscopy: A Meta-analysis of Data From Individual Patients in Randomized Controlled Trials. Gastroenterology 2019;157:462-71.

35. Aziz M, Desai M, Hassan S, et al. Improving serrated adenoma detection rate in the colon by electronic chromoendoscopy and distal attachment: systematic review and meta-analysis. Gastrointest Endosc 2019;90:721-731.e1.

36. Giardiello FM, Allen JI, Axilbund JE, et al. Guidelines on genetic evaluation and management of Lynch syndrome: a consensus statement by the US Multi-society Task Force on colorectal cancer. Am J Gastroenterol 2014;109:1159-79.

37. East JE, Suzuki N, Stavrinidis M, et al. Narrow band imaging for colonoscopic surveillance in hereditary nonpolyposis colorectal cancer. Gut 2008;57:65-70.

38. Cellier C, Perrod G, Colas C, et al. Back-toBack Comparison of Colonoscopy With Virtual Chromoendoscopy Using a Third-Generation NarrowBand Imaging System to Chromoendoscopy With Indigo Carmine in Patients With Lynch Syndrome. Am J Gastroenterol 2019;114:1665-70.

39. Omata F, Ohde S, Deshpande GA, et al. Image-enhanced, chromo, and cap-assisted colonoscopy for improving adenoma/neoplasia detection rate: a systematic review and meta-analysis. Scand J Gastroenterol 2014;49:222-37.

40. Yoshida N, Dohi O, Inoue K, et al. Blue Laser Imaging, Blue Light Imaging, and Linked Color Imaging for the Detection and Characterization of Colorectal Tumors. Gut Liver 2019;13:140-8.

41. Ikematsu H, Sakamoto T, Togashi K, et al. Detectability of colorectal neoplastic lesions using a novel endoscopic system with blue laser imaging: a multicenter randomized controlled trial. Gastrointest Endosc 2017;86:386-94.

42. Shimoda R, Sakata Y, Fujise T, et al. The adenoma miss rate of blue-laser imaging vs. white-light imaging during colonoscopy: a randomized tandem trial. Endoscopy 
2017;49:186-90.

43. Min M, Deng P, Zhang W, et al. Comparison of linked color imaging and white-light colonoscopy for detection of colorectal polyps: a multicenter, randomized, crossover trial. Gastrointest Endosc 2017;86:724-30.

44. Paggi S, Mogavero G, Amato A, et al. Linked color imaging reduces the miss rate of neoplastic lesions in the right colon: a randomized tandem colonoscopy study. Endoscopy 2018;50:396-402.

45. Yoshida N, Hisabe T, Ikematsu H, et al. Comparison Between Linked Color Imaging and Blue Laser Imaging for Improving the Visibility of Flat Colorectal Polyps: A Multicenter Pilot Study. Dig Dis Sci 2020;65:2054-62.

46. Oliveira Dos Santos CE, Malaman D, Pereira-Lima JC, et al. Impact of linked-color imaging on colorectal adenoma detection. Gastrointest Endosc 2019;90:826-34.

47. Fujimoto D, Muguruma N, Okamoto K, et al. Linked color imaging enhances endoscopic detection of sessile serrated adenoma/polyps. Endosc Int Open 2018;6:E322-E334.

48. Leung WK, Guo CG, Ko MKL, et al. Linked color imaging versus narrow-band imaging for colorectal polyp detection: a prospective randomized tandem colonoscopy study. Gastrointest Endosc 2020;91:104-112.e5.

49. Bhandari P, Thayalasekaran S, Keisslich R, et al. Detection and characterization of colorectal polyps using highdefinition white light and i-Scan: Evidence-based consensus recommendations using a modified Delphi process. United European Gastroenterol J 2018;6:748-54.

50. Testoni PA, Notaristefano C, Vailati C, et al. Highdefinition colonoscopy with i-Scan: better diagnosis for small polyps and flat adenomas. World J Gastroenterol 2012;18:5231-9.

51. Kidambi TD, Terdiman JP, El-Nachef N, et al. Effect of I-scan Electronic Chromoendoscopy on Detection

doi: 10.21037/tgh.2020.02.05

Cite this article as: Lee A, Tutticci N. Enhancing polyp detection: technological advances in colonoscopy imaging. Transl Gastroenterol Hepatol 2021;6:61. of Adenomas During Colonoscopy. Clin Gastroenterol Hepatol 2019;17:701-708.e1.

52. Bisschops R, Tejpar S, Willekens H, et al. Virtual chromoendoscopy (I-SCAN) detects more polyps in patients with Lynch syndrome: a randomized controlled crossover trial. Endoscopy 2017;49:342-50.

53. Zhao ZY, Guan YG, Li BR, et al. Detection and miss rates of autofluorescence imaging of adenomatous and polypoid lesions during colonoscopy: a systematic review and metaanalysis. Endosc Int Open 2015;3:E226-35.

54. Takeuchi Y, Sawaya M, Oka S, et al. Efficacy of autofluorescence imaging for flat neoplasm detection: a multicenter randomized controlled trial (A-FLAT trial). Gastrointest Endosc 2019;89:460-9.

55. Moriichi K, Fujiya M, Okumura T. The efficacy of autofluorescence imaging in the diagnosis of colorectal diseases. Clin J Gastroenterol 2016;9:175-83.

56. Vinsard DG, Mori Y, Misawa M, et al. Quality assurance of computer-aided detection and diagnosis in colonoscopy. Gastrointest Endosc 2019;90:55-63.

57. Liedlgruber M, Uhl A. Computer-aided decision support systems for endoscopy in the gastrointestinal tract: a review. IEEE Rev Biomed Eng 2011;4:73-88.

58. Urban G, Tripathi P, Alkayali T, et al. Deep Learning Localizes and Identifies Polyps in Real Time With 96\% Accuracy in Screening Colonoscopy. Gastroenterology 2018;155:1069-1078.e8.

59. Misawa M, Kudo SE, Mori Y, et al. Artificial IntelligenceAssisted Polyp Detection for Colonoscopy: Initial Experience. Gastroenterology 2018;154:2027-2029.e3.

60. Wang P, Berzin TM, Glissen Brown JR, et al. Real-time automatic detection system increases colonoscopic polyp and adenoma detection rates: a prospective randomised controlled study. Gut 2019;68:1813. 